\title{
Polymorphisms of the MTHFR gene in mothers of children with trisomy 21 (Down syndrome) in a Polish population
}

\author{
Paulina Czechowicz, 1,2,B-D,F, Małgorzata Małodobra-Mazur 2,B,C,E, , Arleta Lebioda 2,B,C,F, \\ Anna Jonkisz ${ }^{2, B, C, F}$, Tadeusz Dobosz ${ }^{2, A, F}$, Robert Śmigiel ${ }^{3, A, F}$ \\ ${ }^{1}$ Department of Forensic Medicine, Molecular Techniques Unit, Wroclaw Medical University, Poland \\ ${ }^{2}$ Department od Microbiology, Wroclaw Medical University, Poland \\ ${ }^{3}$ Division of Propaedeutics of Paediatric Rare Disorders, Wroclaw Medical University, Poland \\ A - research concept and design; $\mathrm{B}$ - collection and/or assembly of data; $\mathrm{C}$ - data analysis and interpretation; \\ $\mathrm{D}$ - writing the article; $\mathrm{E}$ - critical revision of the article; $\mathrm{F}$ - final approval of the article
}

Address for correspondence

\section{Paulina Czechowicz}

E-mail: paulina.czechowicz.umedwro@gmail.com

Funding sources

Statutory activity - maintain the research capacity,

Wroclaw Medical University, ST.A122.17.039

Conflict of interest

None declared

Received on 0ctober 30, 2019

Reviewed on November 15, 2019

Accepted on December 5, 2019

Published online on February 19, 2020

Cite as

Czechowicz P, Małodobra-Mazur M, Lebioda A, Jonkisz A, Dobosz T, Śmigiel R. Polymorphisms of the MTHFR gene in mothers of children with trisomy 21 (Down syndrome) in a Polish population. Adv Clin Exp Med. 2020;29(2):251-256. doi:10.17219/acem/115078

DOI

10.17219/acem/115078

Copyright

Copyright by Author(s)

This is an article distributed under the terms of the

Creative Commons Attribution 3.0 Unported (CC BY 3.0)

(https://creativecommons.org/licenses/by/3.0/)

\begin{abstract}
Background. Down syndrome (DS) is the most frequent cause of intellectual disability. In 95\% of cases, it is caused by simple trisomy of chromosome 21 resulting from nondisjunction of chromosomes in meiotic division. Currently, the molecular and cellular mechanisms responsible for the phenomenon of nondisjunction are unknown.

Objectives. To investigate the incidence of 5 single-nucleotide polymorphisms (SNPS) of the MTHFR gene in a population of Polish mothers who had given birth to children with trisomy 21 in comparison with a control group of women with healthy offspring.

Material and methods. The test material comprised venous blood collected from mothers who had given birth to a child with DS (study group, $\mathrm{n}=130$ ) as well as from women who had given birth to children without trisomy 21 (control group, $n=88$ ). DNA was isolated using a kit manufactured by Qiagen. Amplification was carried out using a Qiagen Multiplex PCR Kit (Qiagen); genotyping was performed using SNaPshot Genotyping MasterMix (Applied Biosystems).

Results. No statistically significant differences were observed in the frequency of genotypes between the examined groups in terms of the polymorphisms of the MTHFR gene.

Conclusions. In the Polish population studied, no relationship was found between the occurrence of particular genotypes of the MTHFR gene, i.e., 677CT, 1298AC, rs3737964, rs4846048, and rs1994798, in women and the birth of children with trisomy 21. The results contradict the validity of research on polymorphisms of the MTHFR gene as potential predisposing factors for the occurrence of trisomy 21 in children.
\end{abstract}

Key words: MTHFR, methylenetetrahydrofolate reductase, Down syndrome, simple trisomy of chromosome 21, single nucleotide polymorphism 


\section{Background}

Down syndrome (DS), known as trisomy 21, occurs at an estimated frequency of about 1/650-700 live births and is the most frequent known cause of intellectual disability. The chromosomal aberration associated with DS depends on the presence of an additional chromosome 21, which, in most cases (95\%), is caused by a simple trisomy resulting from the phenomenon of chromosome nondisjunction during meiotic division in the process of gametogenesis in one of the parents. ${ }^{1}$ The additional chromosome 21, in $90-95 \%$ of cases, is of maternal origin; the defective segregation of chromosomes occurs mainly during meiosis I ( $80 \%$ of cases) and less frequently during meiosis II (20\% of cases). ${ }^{2-4}$

Currently, the molecular and cellular mechanisms responsible for the phenomenon of nondisjunction are unknown, as are the potential factors which predispose to its occurrence. The only documented risk factor for giving birth to a child with trisomy 21 is the mother's age (when > 35 years). ${ }^{4,5}$ In 1999, for the first time, studies were published in which it was suggested that polymorphisms within genes coding for enzymes indispensable in folate metabolism might constitute risk factors for chromosomal diseases, including DS. ${ }^{6}$

The products of the metabolism of folates are indispensable compounds used in many cellular processes, primarily in the synthesis of nucleic acid precursors and the methylation of cellular components, mainly DNA. The folate cycle also enables the conversion of homocysteine to methionine. The key enzyme involved in this cycle is the enzyme methylenetetrahydrofolate reductase (MTHFR), which catalyzes the irreversible reduction of 5,10-methylenetetrahydrofolate $(5,10-\mathrm{MTHF})$ to 5-methylenetetrahydrofolate (5-MTHF), a methyl-group donor for homocysteine remethylation and methionine resynthesis. The end result, S-adenosylmethionine (SAM), the product of continued methionine conversion, is the basic compound required for the methylation of nucleic acids. DNA methylation plays a key role in gene expression as well as in cell differentiation. It has been proven that single nucleotide polymorphisms (SNPs) within the MTHFR gene cause a reduction in the activity of this enzyme, resulting in increased levels of homocysteine and in hypomethylation of nucleic acids. ${ }^{1,5-6}$

In vivo studies have demonstrated the influence of epigenetic phenomena, mainly DNA hypomethylation, on the occurrence of instability or incorrect segregation of chromosomes, or of aneuploidy. ${ }^{7,8}$ In vitro studies on cell cultures (plant and animal) have confirmed that insufficient DNA methylation may result in chromosomal instability as well as nondisjunction and aberrations. ${ }^{9,10}$ Similarly, a deficiency or lack of folates in the diet may affect the occurrence of DNA chain breaks and defective gene expression. Thus, researchers have reached the conclusion that folate deficiencies and abnormal expression of the MTHFR gene may pose a risk of chromosomal nondisjunction during meiosis, and, at the same time, increase the risk of trisomy 21 in children. ${ }^{1,5-7}$
The polymorphisms of the SNP type within the MTHFR gene most often researched and described are rs1801133 (677CT) and rs1801131 (1298AC). The former is dependent on the transition of cytosine to thymine at position 677 in the $4^{\text {th }}$ exon of the MTHFR gene. The result is the conversion of alanine to valine in the amino acid chain at position 222 of the protein. The enzyme variant coded in this way is thermolabile and is characterized by reduced activity. ${ }^{11-13}$ The change in rs1801131 occurs within exon 7 and consists of the transversion of adenine to cytosine at position 1298 of mRNA; instead of glutamine, alanine is incorporated at position 429 of the amino acid chain. The regulatory domain binding SAM undergoes modification, resulting in a reduction in the activity of MTHFR. ${ }^{12}$ The authors of the study deemed it justified to take an interest in 3 other polymorphisms within the MTHFR gene: rs3737964, rs4846048 and rs1994798. The $1^{\text {st }}$, rs3737964, is located in the promoter region ( $5^{\prime}$ near gene) of the MTHFR gene and consists of the conversion of guanine to adenine. Sequencing changes in this region may affect the expression of mRNA and the amount of protein (enzyme) produced. The flow of mRNA may also be influenced by the $2^{\text {nd }}$ polymorphism, rs4846048, which is located in the 3'UTR regulatory region and consists of the conversion of adenine to guanine. The last of the studied SNPs, rs1994798, is located within the intron and involves the exchange of cytosine for thymine. Polymorphisms located in introns are probably capable of modifying the expression of other genes or may be linked with other polymorphisms. ${ }^{14-16}$

\section{Objectives}

The study presented here investigated the frequency of 5 SNP-type polymorphisms of the MTHFR gene, 677CT, 1298AC, rs3737964, rs4846048, and rs1994798, in mothers of children with trisomy 21 and in women giving birth to healthy children, with the aim of assessing the relationship between the variability of these polymorphisms and trisomy 21 in a Polish population.

\section{Material and methods}

\section{Research material}

The study group consisted of 130 samples of venous blood collected with the use of ethylenediaminetetraacetic acid (EDTA) from women who had given birth to a child with trisomy 21. Prior to the isolation of DNA, all samples were stored in a freezer at a temperature of $-80^{\circ} \mathrm{C}$. Approval No. KB20/2016 of the Bioethics Commission was granted for molecular tests, and collection of the material lasted from February 2016 to February 2017. All of the women involved expressed their informed consent for their participation in the study. The age of the women at the birth 
of the children with DS ranged from 18 to 41 years, with a mean of 32 years.

The control group consisted of 88 samples of isolated DNA, stored at $-20^{\circ} \mathrm{C}$ at the Molecular Techniques Unit of Wroclaw Medical University, Poland. The DNA was collected in 2010-2012, with approval No. KB-556/2008 of the Bioethics Commission. The samples were taken from women who had given birth to children without trisomy 21 and who gave their informed consent for the use of their genetic material in molecular research. The age of the women ranged from 25 to 78 years, with a mean of 52 years.

\section{Genotyping}

In the case of the study group, first DNA was isolated, using the QIAamp DNA Mini Kit, from Qiagen (Hilden, Germany), according to the manufacturer's instructions. The DNA thus isolated was stored at $-20^{\circ} \mathrm{C}$.

Genetic material was propagated in a multiplex amplification reaction using a Qiagen Multiplex PCR Plus Kit and specific primers in accordance with the manufacturer's instructions. The amplified fragments $(5 \mu \mathrm{L})$ were purified of unused deoxynucleotides and excess primers with $1.5 \mu \mathrm{L}$ of a digestion enzyme mixture: exonucleases I (Exonuclease I 2.7 U; Thermo Fisher Scientific, Waltham, USA) and alkaline phosphatases (FastAP Thermosensitive Alkaline Phosphatase, 1.4 U; Thermo Fisher Scientific), with digestion carried out for $60 \mathrm{~min}$ at $37^{\circ} \mathrm{C}$ and for $15 \mathrm{~min}$ at $80^{\circ} \mathrm{C}$ (for enzyme inactivation).

Detection of polymorphisms was performed by means of mini-sequencing using a SNaPshot Multiplex Kit (Applied Biosystems and Thermo Fisher Scientific) in accordance with the manufacturers' instructions. Minisequencing primers were designed to hybridize to DNA directly at the changed polymorphic site. The sequencing reaction products were also purified of unused dideoxynucleotides using $0.5 \mu \mathrm{L}$ alkaline phosphatase (FastAP Thermosensitive Alkaline Phosphatase, $0.5 \mathrm{U}$; Thermo Fisher Scientific) for $30 \mathrm{~min}$ at $37^{\circ} \mathrm{C}$ and $15 \mathrm{~min}$ at $85^{\circ} \mathrm{C}$.

Detection of mini-sequencing reaction products was carried out by means of capillary electrophoresis in the presence of Hi-Di Formamide (Applied Biosystems) with the addition of $10 \mu \mathrm{L}$ of the internal standard GeneScan-120 LIZ Size Standard (Applied Biosystems). Prior to electrophoresis, the samples were denatured for $5 \mathrm{~min}$ at $95^{\circ} \mathrm{C}$; then the plate was cooled on ice for $3 \mathrm{~min}$. Thus prepared, the plate was placed in a 3130 Genetic Analyzer sequencer (Applied Biosystems) and analysis of the results was conducted using GeneMapper ID v. 3.2 (Thermo Fisher Scientific).

\section{Methods of statistical elaboration}

STATISTICA v. 13.1 (StatSoft, Inc., Tulsa, USA) was used to elaborate the statistical results. Calculations of the frequency of individual genotypes as well as of the incidence of wild and mutant alleles in both studied polymorphic sites in the study and control groups were conducted using the $\chi^{2}$ test. This test was also used to calculate whether the distribution of genotypes obtained in the studied population deviated from the estimated distribution, based on the Hardy-Weinberg principle. A significance level of 0.05 was assumed.

\section{Results}

In the $1^{\text {st }}$ stage of statistical analysis, the studied polymorphisms were checked in terms of maintenance of distributions of genotypes in the population consistent with the Hardy-Weinberg equilibrium (HWE). None of the polymorphisms deviated from HWE; for 677CT, $\mathrm{p}=0.9986 ; 1298 \mathrm{AC}, \mathrm{p}=0.9958 ; \mathrm{rs} 3737967, \mathrm{p}=0.9956$; rs4846048, $\mathrm{p}=0.9982$; and rs1994798, $\mathrm{p}=0.9991$. Based on the results of genotyping obtained for all 130 samples from the study group and 88 samples from the control group, the frequency of individual genotypes at both polymorphic sites was calculated.

In the case of $677 \mathrm{CT}$, the highest percentage in both groups was obtained for CT heterozygotes: $44.5 \%$ in the study group and $60 \%$ in the control group. The homozygous CC genotype constituted $40 \%$ in the study group and $32 \%$ in the control group, while homozygotes representing the TT mutation constituted $15.5 \%$ and $8 \%$, respectively. Statistical analysis of the frequency of polymorphism in the studied groups showed no statistically significant differences $(\mathrm{p}=0.0548)$. The frequency distribution is presented in Fig. 1.

Polymorphism 1298AC was characterized by the following distribution of genotypes in the studied population: in the study group, the homozygous AA configuration accounted for $53 \%$, the heterozygous $\mathrm{AC}$ for $37 \%$, and the homozygous $\mathrm{CC}$ for $10 \%$, whereas, in the control group, these genotypes accounted for $38.5 \%, 51 \%$ and $10.5 \%$ of the population, respectively. In comparing the frequency of the occurrence of genotypes in the studied groups, no statistically significant differences were found according to the $x^{2}$ test $(\mathrm{p}=0.0905)$. The distribution of genotypes for the 1298AC polymorphism is presented in Fig. 1.

At the site of rs3737964, the frequency of individual genotypes was as follows: the homozygous GG configuration constituted $55.5 \%$ in the study group and $40.5 \%$ in the control group; heterozygous GA - 35.5\% and 49\%, respectively; and homozygous AA - $9 \%$ and $10.5 \%$. respectively. Comparison of these frequency distributions using the $\chi^{2}$ test showed no statistically significant differences $(\mathrm{p}=0.0986)$. These distributions are presented in Fig. 1 .

At the polymorphic site of rs4846048, in both the study and control groups, the homozygous AA configuration constituted the largest percentage: $57 \%$ in the study group and $49 \%$ in the control group. AG heterozygotes were recorded at $35.5 \%$ and $40.5 \%$, respectively, mutant GG 

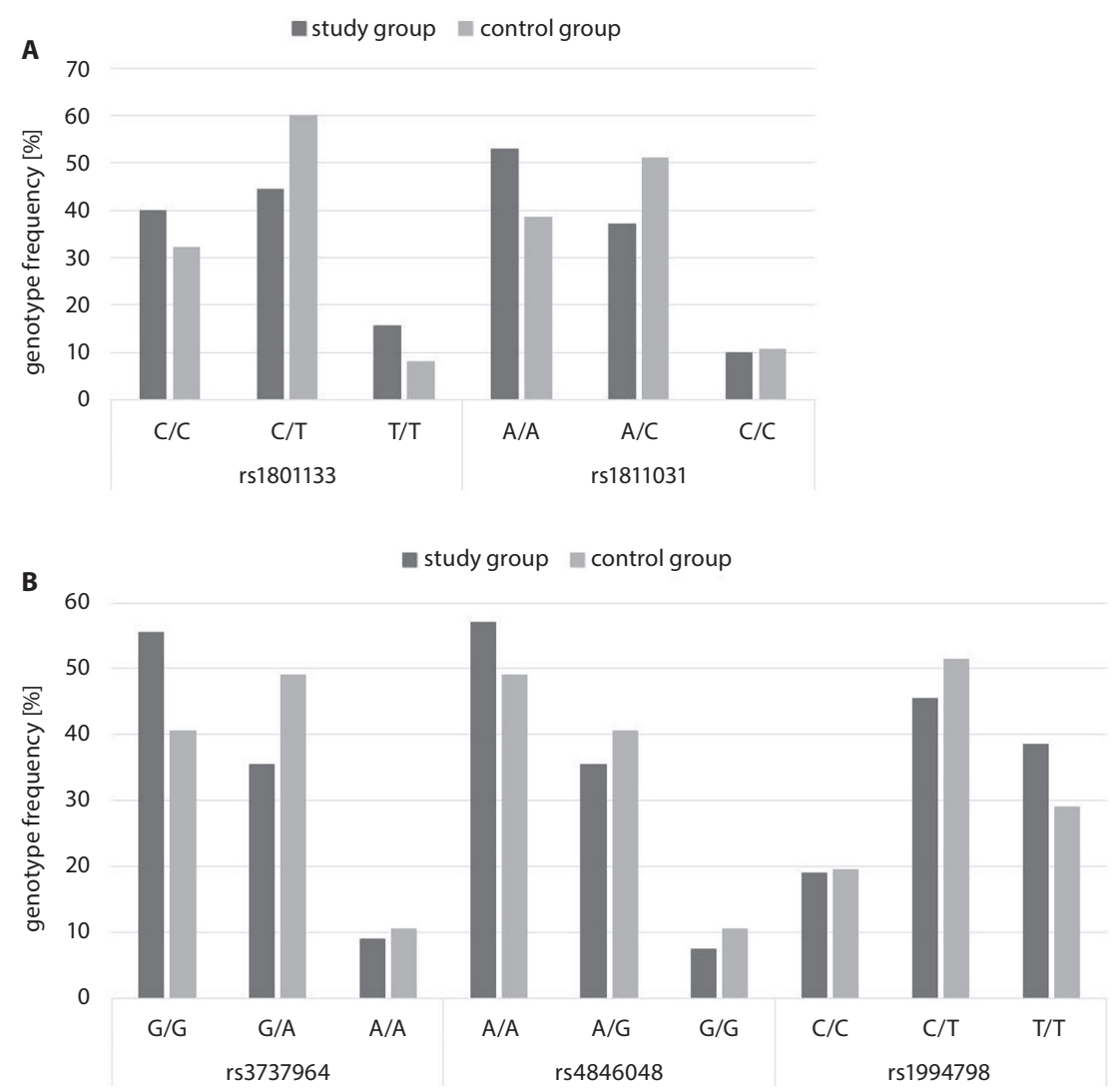

Fig. 1. Genotype frequencies of investigated SNPS in MTHFR gene in study group compared to control group. A - SNPs located in exons; B - SNPs located outside exons, in various functional regions of MTHFR gene

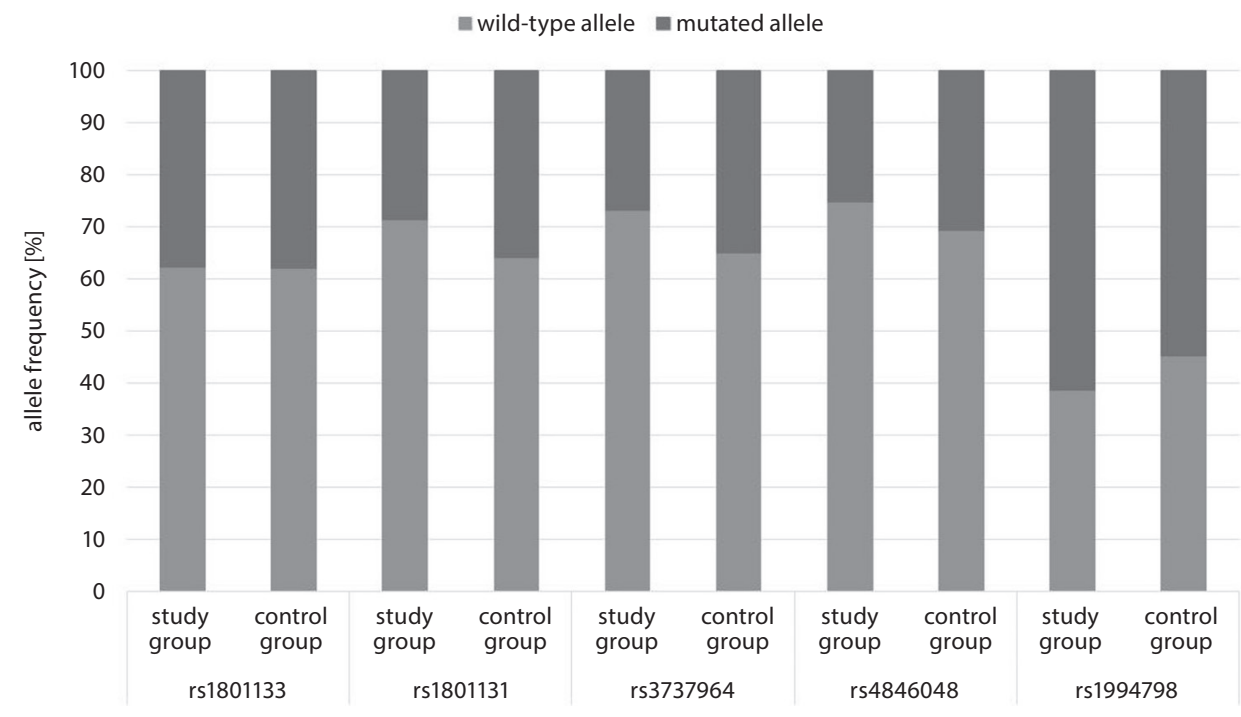

Fig. 2. Frequency of mutant alleles and wild-type alleles in 677CT and 1298AC, as well as rs3737964, rs4846048 and rs1994798, in the study and control groups. The results indicated no statistically significant differences ( $p>0.05$ in all cases)

heterozygotes at $7.5 \%$ and $10.5 \%$, respectively. No statistically significant differences were indicated in the distribution of genotypes $(\mathrm{p}=0.4790)$. The above data is presented in Fig. 1.

The following distribution of genotypes of the rs1994798 polymorphism was observed: for the homozygous CC configuration, $16 \%$ in the study group and $19.5 \%$ in the control group; for CT heterozygotes, $45.5 \%$ in the study group and $51.5 \%$ in the control group. In this case, as well, statistical analysis showed no statistically significant differences $(\mathrm{p}=0.3321)$. The frequency distribution is presented in Fig. 1.
Analysis of the frequency of mutant and wild alleles in the control and study groups also showed an absence of statistically significant differences in the cases of both studied polymorphisms ( $\mathrm{p}>0.05$ ). Wild alleles (C) at $677 \mathrm{CT}$ accounted for $62.5 \%$ in the study group and $62 \%$ in the control group, whereas mutant alleles (A) accounted for $37.7 \%$ and $38 \%$, respectively $(\mathrm{p}=0.9552)$. Similarly, in the case of 1298AC, wild alleles (A) accounted for $71.5 \%$ in the study group and $64 \%$ in the control group, while mutant alleles (C) for $28.5 \%$ in the study group and $36 \%$ in the control group ( $\mathrm{p}=0.2524)$. These frequencies are presented in Fig. 2. 


\section{Discussion}

Trisomy 21 (also called DS) is a relatively common affliction, and the most widely known cause of intellectual disability, hence the investigation and determination of the molecular basis of this disease and the search for potential predisposing factors for its occurrence are justified. Simple trisomy, constituting 95\% of cases, results from the phenomenon of nondisjunction which occurs during meiotic division; however, the mechanisms responsible for the abnormal segregation of chromosomes are still unknown. ${ }^{2}$

In the search for the causes of faulty segregation of chromosomes, their instability, fragility or aneuploidy, an ever greater attention is being drawn to the potential contribution of epigenetic phenomena, primarily DNA hypomethylation. ${ }^{7,8}$ Deficiencies in dietary folate and disorders of the folate cycle which directly result in, i.a., hyperhomocysteinemia and insufficient synthesis of SAM - a fundamental donor of methyl groups necessary for DNA methylation - have been linked to the hypomethylation of nucleic acids. Disorders of the cyclic transformation of folate derivatives result primarily from a defect in the activity of the key enzyme in this cycle, i.e., MTHFR. Currently, more than 40 SNP polymorphisms have been described in the MTHFR gene; the direct influence of some of these on the reduction of the activity of the enzyme encoded by this gene, ultimately resulting in SAM deficiencies and DNA hypomethylation, has been proven. ${ }^{1,5-7,11,17}$ On this basis, a conclusion was drawn regarding the potential for linking nondisjunction, the reason for the vast majority of DS cases, with DNA hypomethylation, which can be brought about by disturbances of the folate cycle resulting from insufficient MTHFR activity, caused in turn by the occurrence of polymorphisms of single nucleotides within the associated gene.

In this study, the 2 SNP polymorphisms most frequently associated with trisomy of chromosome 21 in MTHFR were taken into consideration, namely $677 \mathrm{CT}$ and $1298 \mathrm{AC}$, as well as 3 others, not previously researched for the existence of correlations with DS, namely rs3737964, rs4846048 and rs1994798. Observed differences between the study and control groups in the frequency of genotypes in $677 \mathrm{CT}$ and $1298 \mathrm{AC}$, as well as in all 3 remaining polymorphic sites, showed no statistical significance in the $X^{2}$ test $(p>0.05)$. The distribution of the percentage of frequency of mutant and wild alleles in the studied SNPs also fell within the confidence interval in the $x^{2}$ test $(p>0.05)$; thus, no statistically significant differences were observed in the studied groups in the Polish population.

The results presented in this paper are congruent with many other reports published in the relevant literature since the appearance of the first paper on this subject in 1999. This applies equally to studies of Caucasians and of other populations. Worth mentioning, i.a., are studies on French (Chango et al., 2005), ${ }^{18}$ Italian (Stuppia et al., 2002), ${ }^{19}$ Danish (Kokotas et al., 2009), ${ }^{20}$ and Croatian (Vraneković et al., 2010) ${ }^{21}$ populations. In addition, analogous studies which also excluded the association of DS with the SNP polymorphisms 677CT and 1298AC were carried out in Jordan (Sadiq et al., 2011), ${ }^{22}$ Romania (Bucerzan et al., 2017), ${ }^{6}$ Brazil (Balarin et al., 2017), ${ }^{5}$ Turkey (Boduroglu et al., 2004), ${ }^{23}$ China (Jiajin et al., 2018), ${ }^{1}$ and India (Kohli et al., 2008; Kaur et al., 2013; Mohanty et al., 2012). ${ }^{24-26}$ Confirmation was also obtained in an extensive meta-analysis by Yang et al. (2013), encompassing 32 articles excluding the association of MTHFR polymorphisms of $677 \mathrm{CT}$ and $1298 \mathrm{AC}$ with trisomy of chromosome $21 .^{27}$

On the other hand, an equal number of researchers have proven a relationship between the occurrence of the described polymorphisms in the MTHFR gene in women and the birth of children with DS. This is evidenced by the first study by James et al. (1999) on an American population. ${ }^{7}$ Similar results were obtained by Cyril et al. (2009, southern India), ${ }^{28}$ Coppedè et al. (2009, Italy), ${ }^{29}$ Meguid et al. (2008, Egypt), ${ }^{30}$ and da Silva et al. (2005, Brazil). ${ }^{31}$ Mention may also be made of meta-analyses conducted by Wu et al. (2012), ${ }^{32}$ Rai et al. (2014) ${ }^{33}$ and Victorino et al. (2014). ${ }^{34}$

The glaring discrepancies between these reports renders any inferences about single nucleotide polymorphisms $677 \mathrm{CT}$ and $1298 \mathrm{AC}$ as potential predisposing factors for the occurrence of DS in children doubtful and controversial, at the very least. The present paper also indicates the absence of any connection between the other 3 polymorphisms (rs3737964, rs4846048 and rs1994798) and the occurrence of DS. All of the abovementioned authors emphasize that these discrepancies exclude SNPs in the MTHFR gene as an independent risk factor for trisomy 21. The polymorphisms in question may nevertheless constitute one of many factors, including additional genetic, epigenetic, environmental, and other random factors, whose simultaneous interaction may result in a predisposition to the birth of a child with trisomy $21 .^{29}$

The results of the present study of a Polish population do not contradict the reports published to date. It is not out of the question that larger sample size (in both the test and control groups) would result in statistically significant differences between the frequencies of individual genotypes of 677CT and 1298AC in the studied groups, given that the results of statistical analysis in some comparisons were close to decisive values. However, neither does the exclusion of a relationship between these polymorphisms in the MTHFR gene in mothers and the birth of children with trisomy 21 in this Polish population equate to the lack of participation of the described changes in the molecular basis of DS. The most appropriate direction of research appears to be an investigation of the simultaneous influence of several factors in the pathomechanism of DS; this would require additional, extremely detailed analyses. 


\section{Conclusions}

In the present paper, no correlation was observed between the occurrence of polymorphisms in the MTHFR gene in mothers and the birth of children with DS in a Polish population. The results contradict the validity of research on the 677CT and 1298AC (as well as rs3737964, rs4846048, and rs1994798) polymorphisms of the MTHFR gene as potential predisposing factors for the occurrence of trisomy 21 in children.

\section{ORCID iDs}

Paulina Czechowicz (1) https://orcid.org/0000-0002-1693-484X Małgorzata Małodobra-Mazur (i) https://orcid.org/0000-0002-9864-5928 Arleta Lebioda (10) https://orcid.org/0000-0001-5802-2155 Anna Jonkisz (10) https://orcid.org/0000-0001-6916-4212 Tadeusz Dobosz (1) https://orcid.org/0000-0003-0413-9109 Robert Śmigiel (1) https://orcid.org/0000-0003-2930-9549

\section{References}

1. Jiajin L, Shuyan C, Junxiao C, Xiudi W. Genetic polymorphisms in folate metabolism as risk for Down syndrome in the southern China. J Matern Fetal Neonatal Med. 2019:32(12):2030-2035.

2. Tobias ES, Connor M, Ferguson-Smith M. Wrodzone wady rozwojowe. In: Latos-Bieleńska A, ed. Genetyka medyczna. $3^{\text {rd }}$ ed in Polish. Warszawa, Poland: PZWL; 2014:250.

3. Ferenc T, Bratkowska W, Pacholczyk M, Jakubowski L. Zespoły aberracji chromosomowych. In: Ferenc T, Drewa G. Genetyka medyczna. Podręcznik dla studentów. Wrocław, Poland: Elsevier Urban \& Partner; 2011:479-481.

4. Maitra A. Choroby uwarunkowane genetycznie i choroby wieku dziecięcego. In: Olszewski W, ed. Kumar V, Abbas AK, Aster JC. Robbins. Patologia. $2^{\text {nd }}$ ed. in Polish. Wrocław, Poland: Edra Urban \& Partner; 2017:259-260.

5. Balarin M, Cintra M, Cordeiro F, Naves L, Silva-Grecco R. Screening of six polymorphisms related with folate metabolism in parents of individuals with Down syndrome. J Matern Fetal Neonatal Med. 2017:1-191.

6. Bucerzan S, Popp RA, Vlad RM, Lazea C, Nicolaescu R, GrigorescuSido P. Evaluation of C677T and A1298C polymorphism of the methylenetetrahydrofolate reductase gene as a maternal risk factor for trisomy 21. Revista Romana de Medicina de Laborator. 2017;25:1.

7. James SJ, Pogribna M, Pogribny IP, et al. Abnormal folate metabolism and mutation in the methylenetetrahydrofolate reductase gene may be maternal risk factors for Down syndrome. Am J Clin Nutr. 1999;70(4):495-501.

8. Guang-zhi Q, Grundy PE, Narayan A, Ehrlich M. Frequent hypomethylation in Wilms tumors of pericentromeric DNA in chromosomes 1 and 16. Cancer Genet Cytogenet. 1999;109(1):34-39.

9. Harrison JJ, Anisowicz A, Gadi IK, Raffeld M, Sager R. Azacytidineinduced tumorigenesis of CHEF/18 cells: Correlated DNA methylation and chromosome changes. Proc Natl Acad SciUS A. 1983;80(21):66066610.

10. Lengauer C, Kinzler KW, Vogelstein B. DNA methylation and genetic instability in colorectal cancer cells. Proc Natl Acad Sci. 1997;94(6): 2545-2550.

11. Kurzawińska G, Seremak-Mrozikiewicz A, Drews K, Barlik M, Mrozikiewicz PM. Genetic conditioned changes in activity of 5,10-methylenetetrahydrofolate reductase (MTHFR) and recurrent miscarriages. Ginekol Pol. 2009;80(10):762-767.

12. Seremak-Mrozikiewicz A. The significance of folate metabolism in complications of pregnant women [in Polish]. Ginekol Pol. 2013;84(5): 377-384.

13. Internet database SNP. SNPedia. http://www.snpedia.com/index. php/SNPedia. Accessed May 30, 2018.

14. Internet database SNP. National Center for Biotechnology Information. https://www.ncbi.nlm.nih.gov/SNP/snp_ref.cgi?chooseRs=all\& locusld $=4524 \& \mathrm{mrna}=$ NM_005957.4\&ctg=NT_032977.10\&prot=NP 005948.3\&orien=reverse\&refresh=refresh. Accessed May 30, 2018.
15. Xiaogang L, Lan-Juan Z, Yong-Jun L, Dong-Hai X, Recker RR, HongWen D. The MTHFR gene polymorphism is associated with lean body mass but not fat body mass. Hum Genet. 2008;123(2):189-196.

16. Janusz P. Polimorfizmy genów receptorów estrogenowych u chorych z postacia progresywna i nieprogresywna skoliozy idiopatycznej [doctoral dissertation]. Poznan University of Medical Sciences; 2014.

17. Magnowski P, Seremak-Mrozikiewicz A, Nowak-Markwitz E, Kurzawińska G, Drews K, Spaczyński M. No association between MTHFR 677C $>T$ polymorphism and ovarian cancer risk in BRCA1 mutation carries in Wielkopolska region [in Polish]. Ginekol Pol. 2010;81(77):506-510.

18. Chango A, Fillon-Emery N, Mircher C, et al. No association between common polymorphisms in genes of folate and homocysteine metabolism and the risk of Down's syndrome among French mothers. Brit J Nutr. 2005;94(2):166-169.

19. Stuppia L, Gatta V, Gaspari AR, et al. C677T mutation in the 5,10-MTHFR gene and risk of Down syndrome in Italy. Eur J Hum Genet. 2002; 10(6):388-390.

20. Kokotas H, Grigoriadou M, Mikkelsen M, Giannoulia-Karantana A, Petersen MB. Investigating the impact of Down syndrome related common MTHFR 677 C $>$ T polymorphism in the Danish population. Dis Markers. 2009;27(6):279-285.

21. Vraneković J, Babić Božovićl, Starcevic Cizmarevic N, et al. Functional interference of methylenetetrahydrofolate reductase gene polymorphisms on enzyme stability as a potential risk of Down syndrome in Croatia. Dis Markers. 2010;28(5):293-298.

22. Sadiq MF, Al-Refai EA, Al-Nasser A, Khassawneh M, Al.-Batayneh Q. Methylenetetrahydrofolate reductase polymorphisms C677T and A1298C as maternal risk factors for Down syndrome in Jordan. Genet Test Mol Bioma. 2011;15(1-2):51-57.

23. Boduroglu K, Alanay Y, Koldan B, Tuncbilek E. Methylenetetrahydrofolate reductase enzyme polymorphisms as maternal risk for Down syndrome among Turkish women. Am J Med Genet. 2004;127A(1): 5-10.

24. Kohli U, Arora S, Kabra M, Ramakrishnan L, Gulati S, Pandey RM. Prevalence of MTHFR C677T polymorphism in north Indian mothers having babes with trisomy 21 Down syndrome. Down Syndrome Research Pract. 2008;12(2):133-137.

25. Kaur A, Kaur A. Prevalence of methylenetetrahydrofolate reductase 677 C-T polymorphism among mothers of Down syndrome children. Indian J Hum Genet. 2013;19(4):412-414.

26. Mohanty PK, Kapoor S, Dubey AP, et al. Evaluation of C677T polymorphism in methylenetetrahydrofolate reductase gene and its association with levels of serum homocysteine, folate, and vitamin $B_{12}$ as maternal risk of Down syndrome. Indian J Hum Genet. 2012;18(3): 285-289.

27. Yang $M$, Gong T, Lin X, et al. Maternal gene polymorphisms involved in folate metabolism and the risk of having a Down syndrome offspring: A meta-analysis. Mutagenesis. 2013;28(6):661-671.

28. Cyril C, Rai P, Chandra N, Giponath PM, Satyamoorthy K. MTHFR gene variants C677T, A1298C and association with Down syndrome: A casecontrol study from South India. Indian J Hum Genet. 2009;15(2):61-64.

29. Coppedè $F$. The complex relationship between folate/homocysteine metabolism and risk of Down syndrome. Mutat Res. 2009;682(1): 54-70.

30. Meguid NA, Dardir A, Khass M, El Hossieny L, Ezzat A, El Awady MK. MTHFR genetic polymorphism as risk factor in Egyptian mothers with Down syndrome children. Dis Markers. 2008;24(1):19-26.

31. da Silva LRJ, Vargani N, de Camargo Galdieri L, et al. Relationship between polymorphisms in genes involved in homocysteine metabolism and maternal risk for Down syndrome in Brazil. Am J Med Genet. 2005;135(3):263-267.

32. Wu X, Wang X, Chan Y, Jia S, Luo Y, Tang W. Folate metabolism gene polymorphisms MTHFR C677T and A1298C and risk for Down syndrome offspring: A meta-analysis. Eur J Obstet Gyn Reprod Biol. 2013; 167(2):154-159.

33. Rai V, Yadav U, Kumar P, Yadav SK, Mishra OP. Maternal methylenetetrahydrofolate reductase C677T polymorphism and Down syndrome risk: A meta-analysis from 34 studies. PLoS One. 2014;9(9):e10855.

34. Victorino DB, Godoy MF, Goloni-Bertollo EM, Pavarino EC. Meta-analysis of methylenetetrahydrofolate reductase maternal gene in Down syndrome: Increased susceptibility in woman carriers of the MTHFR 677T allele. Mol Biol Rep. 2014;41(8):5491-5450. 